\title{
Secondary Structural Elements of the HCV X-region Involved in Viral Replication
}

\author{
Nidhi Gupta, Catherine H. Wu and George Y. Wu* \\ Department of Medicine, Division of Gastroenterology-Hepatology, University of Connecticut Health Center, Farmington, CT, USA
}

\begin{abstract}
Background and Aims: The noncoding regions in the $3^{\prime}-$ untranslated region (UTR) of the hepatitis C virus (HCV) genome contain secondary structures that are important for replication. The aim of this study was to identify detailed conformational elements of the X-region involved in $\mathrm{HCV}$ replication. Methods: Ribonucleic acid (RNA) structural analogs $\mathrm{X} 94, \mathrm{X} 12$, and $\mathrm{X} 12 \mathrm{C}$ were constructed to have identical conformation but $94 \%, 12 \%$, and $0 \%$ sequence identity, respectively, to the $X$ region of HCV genotype $2 a$. Effects of structural analogs on replication of HCV genotypes $1 b$ and $2 a$ HCV RNA were studied by quantitative reverse transcriptase polymerase chain reaction. Results: In replicon BB7 cells, a constitutive replication model, HCV RNA levels decreased to $55 \%, 52 \%, 53 \%$, and $54 \%$ after transfection with expression plasmids generating RNA structural analogs $5 \mathrm{~B}-46, \mathrm{X}-94, \mathrm{X}-12$, and $\mathrm{X}-12 \mathrm{c}$, respectively $(p<0.001$ for all). In an HCV genotype $2 a$ infection model, RNA analogs $5 B-46$, $X-94$, and $X-12$ in hepatic cells inhibited replication to $11 \%$, $9 \%$, and $12 \%$, respectively. Because the X-12 analog was only $12 \%$ identical to the corresponding sequence of $\mathrm{HCV}$ genotype $2 \mathrm{a}$, the sequence per se, or antisense effects were unlikely to be involved. Conclusions: The data suggest that conformation of secondary structures in $3^{\prime}$-UTR of HCV RNA genome is required for HCV replication. Stable expression of RNA analogs predicted to have identical stem-loop structures might inhibit HCV infection of hepatocytes in liver and may represent a novel approach to design anti-HCV agents.

(C) 2015 The Second Affiliated Hospital of Chongqing Medical University. Published by XIA \& HE Publishing Ltd. All rights reserved.
\end{abstract}

\footnotetext{
Keywords: HCV RNA genome; HCV X-region; Hepatitis C virus; Infection; Japanese Fulminant Hepatitis Virus; RNA secondary structure.

Abbreviations: 3'UTR, 3'-untranslated regions; CDNA, complementary deoxyribonucleic acid; CREs, cis-acting replication elements; CMV, cytomegalovirus; DMEM, Dulbecco's Modified Eagle Medium; FBS, fetal bovine serum; HCV, hepatitis C virus; JFH-1, Japanese Fulminant Hepatitis Virus-1; LDHA, lactate dehydrogenase A; MTT, 3-(4,5-dimethylthiazol-2-YI)-2,5-diphenyltetrazolium bromide; NS, nonstructural; nt, nucleotide; PBS, phosphate buffered saline; qRT-PCR, quantitative reverse transcriptase polymerase chain reaction; RNA, ribonucleic acid; UTR, untranslated region.

Received: 02 February 2015; Revised: 26 February 2015; Accepted: 01 March 2015 DOI: $10.14218 / \mathrm{JCTH} .2015 .00003$.

* Correspondence to: George Y. Wu, Department of Medicine, Division of Gastroenterology-Hepatology, University of Connecticut Health Center, 263 Farmington Ave, Farmington, CT 06030-1845, USA. Tel: $+1-800-535-6232 ;+1-$ 860-679-7692, Fax: +1-860-679-3159, E-mail: wu@uchc.edu
}

Introduction

Hepatitis C virus (HCV) is a ribonucleic acid (RNA) virus that causes chronic hepatitis and liver failure, worldwide. ${ }^{1,2}$ It consists of six different genotypes that are differentially distributed geographically. ${ }^{3,4}$ Success of treatment varies greatly depending on the genotype. ${ }^{4,5}$ The genome contains cis-acting replication elements (CREs) that are critical for HCV RNA replication and translation. ${ }^{6,7}$ RNA structural elements present in $5^{\prime}$ - and $3^{\prime}$-untranslated regions ( $3^{\prime}$ UTR) of the HCV genome interact with viral and cellular proteins to initiate and facilitate the replication and translation processes. $^{8-11}$ In our previous studies, we showed that RNA secondary structure of the nonstructural (NS)5B coding region of the HCV genome was required for HCV RNA replication, and hence viral particle production. ${ }^{12-15}$ It has been shown that the $X$ region in the $3^{\prime}$-UTR of the HCV RNA genome contains a highly conserved sequence. ${ }^{16}$ The latter have also been found to form stable secondary stem-loop structures that require physical contact between its RNAdependent RNA polymerase for HCV replication. ${ }^{17-19}$ We hypothesized that RNA structural analogs resembling secondary stem-loop structure of the $\mathrm{X}$ region could be created that can compete with natural HCV genomic structure for binding to proteins and inhibit HCV replication. The aim of this study was to introduce RNA structural analogs resembling these CREs into human liver cells and to identify secondary structural elements of the HCV X-region involved in $\mathrm{HCV}$ replication and infection.

Materials and methods

\section{Cell culture}

In order to identify important secondary structural elements, the effects of HCV structural analogs on HCV replication in two model cell lines were studied: a constitutive replication model and an infection model. In addition, to evaluate whether differences in viral genotype could affect the possible interactions of structural analogs, viruses representing two different genotypes 1 and 2, were studied.

\section{A genotype 1 b BB7 constitutive replication system}

Replicon cells, BB7, a cell culture system containing the HCV genotype $1 \mathrm{~b}$ genome, were obtained from Apath (St. Louis, USA). ${ }^{20,21}$ Cells were maintained in Dulbecco's Modified Eagle Medium (DMEM) supplemented with antibiotic/antimycotic solution (Invitrogen, USA), 10\% fetal bovine serum (FBS) and $0.5 \mathrm{mg} / \mathrm{mL} \mathrm{G} 418$. 


\section{A Japanese Fulminant Hepatitis Virus-1 (JFH-1) HCV infection system}

For JFH-1 HCV genotype 2a studies, Huh7.5 cells (human hepatoma cell line) (obtained from Dr. Charles Rice, Rockefeller University, NY, USA) were maintained in DMEM supplemented with antibiotic/antimycotic solution and $10 \%$ FBS. JFH-1 complementary deoxyribonucleic acid (CDNA), an HCV genotype 2a strain, from Dr. Takaji Wakita (National Institute of Infectious Diseases, Tokyo, Japan) $)^{22-24}$ was used to produce infectious HCV viral particles in Huh7.5. 25,26 To make JFH-1 HCV stocks for infection, Huh 7.5 cells were infected with JFH-1 HCV. Media were collected 5 days postinfection and centrifuged at $1000 \times \mathrm{g}$ for $20 \mathrm{~min}$ to remove debris. JFH-1 HCV in media was concentrated with a centrifugal device (100K NMWL, Amicon ultra, Millipore, USA). Stocks were frozen at $-80{ }^{\circ} \mathrm{C}$ until further use. Infectivity levels of viral stocks were checked by quantitation of JFH-1 HCV RNA in media $48 \mathrm{~h}$ post-infection of Huh7.5 cells with HCV genotype 2a specific primers (Table 1 ) using real time reverse transcriptase polymerase chain reaction (RT-PCR). The PCR conditions were: one cycle of 2 min at 50 $\&$ and $10 \mathrm{~min}$ at $95^{\circ} \mathrm{C}$ followed by 40 cycles of $15 \mathrm{sec}$ at $95{ }^{\circ} \mathrm{C}$ and $1 \mathrm{~min}$ at $60^{\circ} \mathrm{C}$. Specificity of all designed primers was determined with PCR amplification and sequencing of amplified product (data not shown). Melt curve analysis was performed following each RT-PCR to identify the presence of primer dimers and analyze the specificity of the reaction.

\section{RNA structural analogs}

RNA structural analog X-94 was designed to be $100 \%$ identical to the (+) strand of X-region (9508-9605 nucleotides (nt)) on the $3^{\prime}$-end of the HCV genotype $1 \mathrm{~b}$ ( $94 \%$ identical to genotype 2a) genome (Fig. 1A). To determine whether stemloop structures versus specific sequences of HCV of RNA were most important in HCV replication, base pair changes, described below, were made in stems (analog $X-12$ ) and loops (analog X-12C) of analog X-94 (Fig. 1B and 1D). Several software products are available for prediction of secondary structures of RNA based on thermodynamic parameters. Because of its high reliability and reproducibility, Mfold ver 3.2 was used in the current study. ${ }^{27-29}$ RNA structural analogs $\mathrm{X}-12$ and $\mathrm{X}-12 \mathrm{c}$ were predicted to adopt stem-loop structure identical to analog X-94 (Fig. 1B and 1D). Table 3 shows the percent identity of the various RNA structural analogs with $\mathrm{HCV}$ genotypes $1 \mathrm{~b}$ and $2 \mathrm{a}$. To determine the minimal structure of the X-region that could inhibit HCV RNA replication, shorter RNA structural analogs $X-12 a$ and $X-12 b$ (Fig. 1C) were designed that were predicted to retain individual stem-loop structures of analog X-94. ${ }^{27-29}$ All analogs were named based on HCV genome region studied and sequence homology of the analogues relative to the JFH-1 HCV genotype 2a genome.

\section{Cloning and expression}

For expression studies, the $\mathrm{X}-94$ sequence was subcloned into a pSilencer 4.1 cytomegalovirus (CMV) puro plasmid (Ambion, USA), as previously described. ${ }^{12}$ pSilencer 4.1 CMV puro plasmid enables high level expression of cloned hairpin short RNA templates. Expression vectors for RNA structural analogs $\mathrm{X}-12$ and $\mathrm{X}-12 \mathrm{c}$ were constructed from a plasmid expressing the RNA analog X-94 using a QuikChange II Site-Directed Mutagenesis Kit (Agilent Technologies, Inc. USA) according to manufacturer's instructions. Fig. 1B shows nucleotide replacements made in stems of analog X-94 resulting in analog X12, and Fig. 1D illustrates nucleotide replacements made in loops of analog X-12 to construct analog X-12c. Shorter RNA structural analogs $\mathrm{X}-12 \mathrm{a}$ and $\mathrm{X}-12 \mathrm{~b}$ (Fig. 1C) were constructed from a plasmid expressing RNA analog $X-12$ using a QuikChange II Site-Directed Mutagenesis Kit. These sequences were selected as non-overlapping fragments of $X$ 12 that were individually predicted by Mfold to retain all the structural elements present in the parent $X-12$ analog. 5B-74 RNA analog, which was previously shown to inhibit viral genome replication ${ }^{12}$ was used as a positive control for inhibition of viral replication, and a plasmid expressing an unrelated sequence, $\mathrm{HB}$, from hepatitis $B$ virus was used as negative control. An RNA structural analog 5B-46 was predicted to adopt stem-loop structures identical to analog 5B-74 as determined by Mfold, and was constructed using a plasmid expressing RNA analog 5B-74 with QuikChange II Site-Directed Mutagenesis Kit. Sequences of each analog in pSilencer 4.1 CMV puro plasmid (Ambion) were verified with CMV puro primers (Table 1 ) as recommended by the manufacturer.

For BB7 HCV genotype $1 \mathrm{~b}$ replicon studies, cells were plated in 6 -well plates 2 days before transfection. Seventy-five percent confluent cells were transfected with various amounts of each plasmid to generate RNA structural analogs individually or in combinations using lipofectamine (Life Technologies) according to manufacturer's instructions. In brief, lipofectamine and plasmid DNA were separately diluted in Opti-MEM I medium (Invitrogen) without serum. After 15 min incubation,

Table 1. Sequences of primers used for quantification

\begin{tabular}{ll}
\hline Primers & Sequences \\
\hline LDHA FW & 5' TAATGAAGGACTTGGCAGATGAACT 3' \\
LDHA RV & 5' ACGGCTTCTCCCTCTTGCT 3' \\
HCV1b FW & 5' CTGTCTTCACGCAGAAAGCG 3' \\
HCV1b RV & 5' CACTCGCAAGCACCCTATCA 3' \\
CMV puro FW & 5' AGGCGATTAAGTTGGGTA 3' \\
CMV puro RV & 5' CGGTAGGCGTGTACGGTG 3' \\
JFH1 HCV FW & 5' TAGGAGGGCCCATGTTCAAC 3' \\
JFH1 HCV RV & 5' CCCCTGGCTTCTGAGATGAC 3' \\
\hline
\end{tabular}

CMV, cytomegalovirus; FW, forward; HCV, hepatitis C virus; JFH-1, Japanese Fulminant Hepatitis Virus-1; LDHA, lactate dehydrogenase A; RV, reverse. 
A

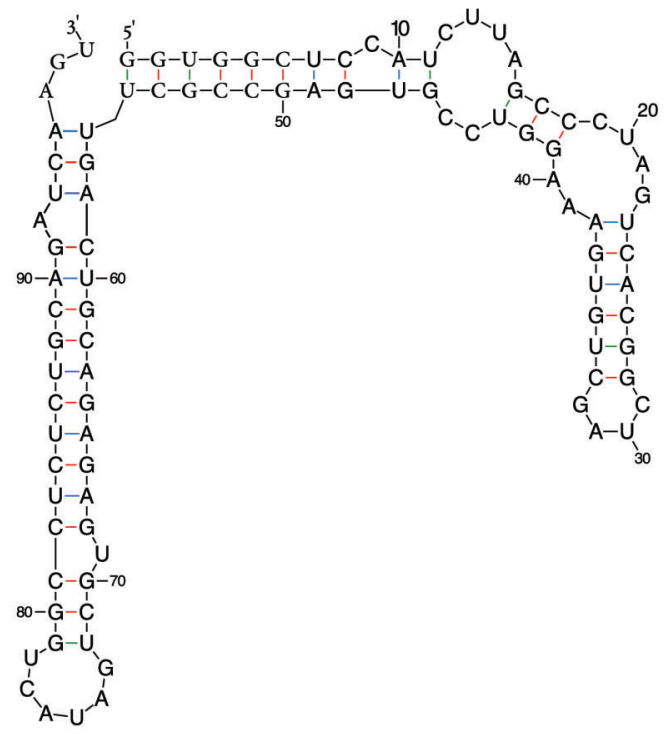

$\mathrm{C}$

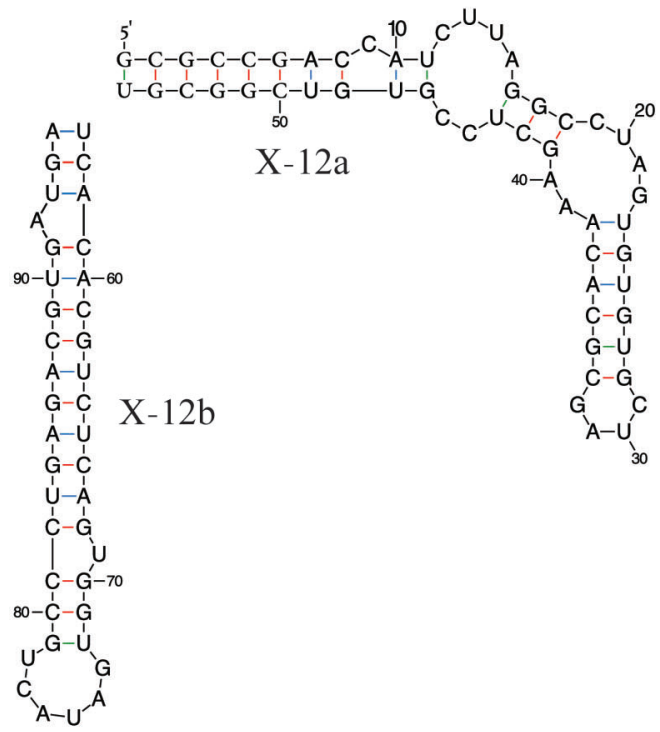

B

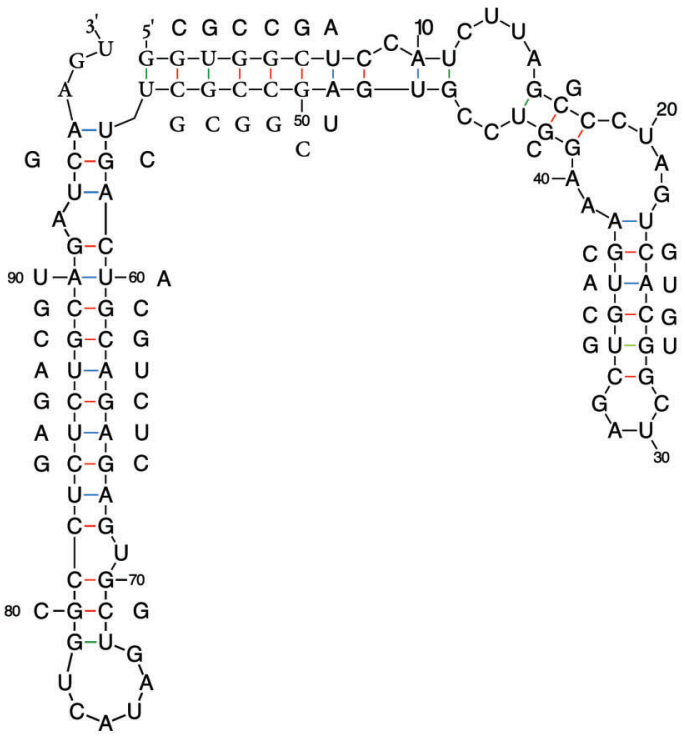

D

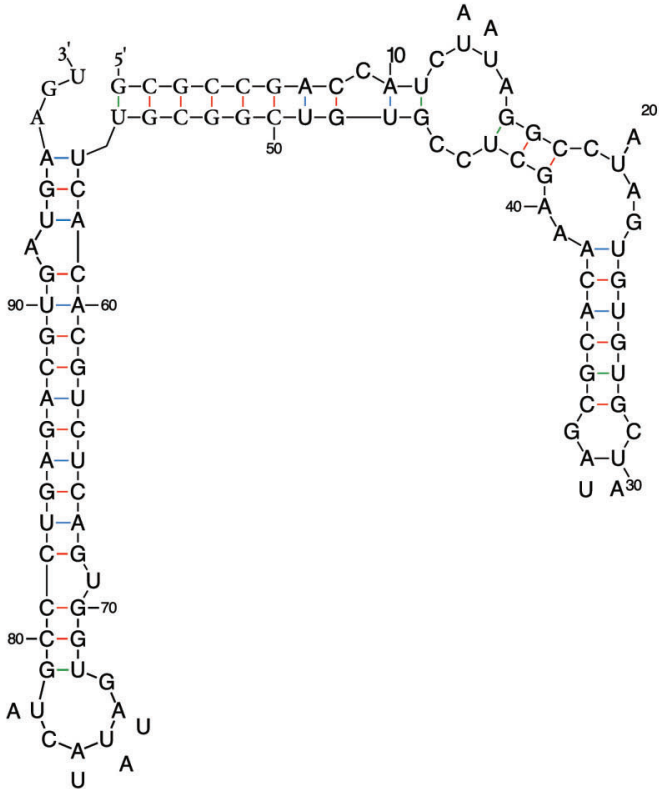

Fig. 1. A, a diagram of the Mfold ver3.2 computed secondary structure of analog X-94; $B$, a diagram of nt replacements made in the stems of analog X-94 to construct analog $X-12$ (secondary structure of $X-12$ was predicted identical to $X-94$ ); $C$, a diagram of analogs $X-12 a$ and $X-12 b$, non-overlapping fragments of analog X-12; $D$, a diagram of nucleotide replacements made in loops of analog $X-12$ to construct analog $X-12 c$ (secondary structure of $X-12 c$ was predicted to be identical to $X-94)$.

they were combined, incubated for 20 min at room temperature, and added to cells in varying concentrations. Cells were harvested $48 \mathrm{~h}$ post-transfection with Trizol (Invitrogen), and HCV RNA levels quantitated in the cell lysates.

For HCV genotype 2a infection studies, two models were used: transfection into cells with a pre-existing infection and transfection into cells before infection. For pre-existing JFH-1 HCV infection studies, $75 \%$ confluent Huh7.5 cells were infected with $\mathrm{JFH}-1 \mathrm{HCV}$ for $8 \mathrm{~h}$ and then transfected with plasmids expressing RNA structural analogs with lipofectamine, as described above. In brief, cells were washed with phosphate buffered saline (PBS). Lipofectamine and plasmid
DNA were separately diluted in Opti-MEM I medium without serum. After a 15 min incubation, they were combined, and incubated for $20 \mathrm{~min}$ at room temperature before being added to cells. Culture medium, $200 \mu \mathrm{L}$, was collected for quantification of JFH-1 HCV levels, and replaced with fresh $200 \mu \mathrm{L}$ of cell culture medium at $0,4,8,12,24,36,48$, and $72 \mathrm{~h}$ of transfection.

For before infection studies, $75 \%$ confluent Huh7.5 cells in 6 -well plates were transfected with $16 \mu \mathrm{g}$ of each plasmid expressing RNA structural analogs, as described above. Cells were then infected with JFH-1 HCV $48 \mathrm{~h}$ post-transfection. After $8 \mathrm{~h}$ of infection, cells were washed twice with PBS to 
Gupta N. et al: RNA structures involved in viral replication

Table 2. Sequences of RNA structural analogs

\begin{tabular}{|c|c|}
\hline RNA analog & Sequences \\
\hline X94 & $\begin{array}{l}\text { GGUGGCUCCAUCUUAGCCCUAGUCACGGCUAGCUGUGAAAGGUCCGUGAGCCGCUUGACUGCAGAGAGU- } \\
\text { GCUGAUACUGGCCUCUCUGCAGAUCAAGU }\end{array}$ \\
\hline $\mathrm{X} 12$ & $\begin{array}{l}\text { GCGCCGACCAUCUUAGGCCUAGUGUGUGCUAGCGCACAAAGCUCCGUGUCGGCGUUCACACGUCUCAGU- } \\
\text { GGUGAUACUGCCCUGAGACGUGAUGAAGU }\end{array}$ \\
\hline $\mathrm{X} 12 \mathrm{a}$ & GCGCCGACCAUCUUAGGCCUAGUGUGUGCUAGCGCACAAAGCUCCGUGUCGGCGU \\
\hline $\mathrm{X} 12 \mathrm{~b}$ & UCACACGUCUCAGUGGUGAUACUGCCCUGAGACGUGAUGA \\
\hline $\mathrm{X} 12 \mathrm{c}$ & $\begin{array}{l}\text { GCGCCGACCAUCAAAGGCCAAGUGUGUGCAUGCGCACAAAGCUCCGUGUCGGCGUUCACACGUCUCAGU- } \\
\text { GGUGUAUCAGCCCUGAGACGUGAUGAAGU }\end{array}$ \\
\hline HB & $\begin{array}{l}\text { CAAAUUCUUUAUAAGGGUCAAUGUCCAUGCCCCAAAGCCACCCAAGGCACAGCUUGGAGGCUUGAACAGU- } \\
\text { GGGACAUGUACAAGAGAUGAUUAGGCAGAGGUG }\end{array}$ \\
\hline $5 B-74$ & $\begin{array}{l}\text { CCGGCUGCGUCCCAGUUGGAUUUAUCCAGCUGGUUCGUUGCUGGUUACAGCGGGGGAGACAUAUAUCA- } \\
\text { CAGCCUGUCUCGUGCCCGACCCCGCUG }\end{array}$ \\
\hline $5 B-46$ & $\begin{array}{l}\text { CGGCGGGGCGCGGGCUUCGAUUUAUCGAGGUCCGCGCCUCGCCGUUACGCGCCCGGCCGGAUAUAUCA- } \\
\text { CAGCCUCCGGCGUGCCCGACGGGCGCG }\end{array}$ \\
\hline
\end{tabular}

remove input JFH-1 HCV. Culture medium, $200 \mu \mathrm{L}$, was collected for quantification of JFH-1 HCV levels and replaced with fresh $200 \mu \mathrm{L}$ of cell culture medium at $0,4,8,12,24,36$, 48 , and $72 \mathrm{~h}$ of infection.

\section{Quantitative RT-PCR ( $R R T-P C R$ )}

For BB7 HCV genotype 1b studies, whole cell RNA was isolated from replicon cell lysates with an RNeasy kit (Qiagen, Germany) according to manufacturer's instructions and treated with RNase free DNase (Invitrogen). cDNA was synthesized using $4 \mu \mathrm{g}$ DNase treated RNA with SuperScript III First-Strand kit (Invitrogen) and quantified by real time RT-PCR with Power SYBR Green PCR Master Mix (Applied Biosystems, USA) using HCV genotype $1 \mathrm{~b}$ specific primers (Table 1) according to manufacturer's instructions. Human lactate dehydrogenase A (LDHA) mRNA levels were quantified in each sample to normalize HCV RNA levels using human LDHA specific primers (Table 1). Assays were done in quadruplicate, and results expressed as mean \pm standard error of HCV RNA levels in cells transfected with analogs compared to untreated controls.

For JFH-1 HCV infection studies, viral RNA was extracted from $200 \mu \mathrm{L}$ media collected from infected cells with a QIAamp Viral RNA kit (Qiagen, Germany) according to manufacturer's instructions. CDNA was synthesized using $4 \mu \mathrm{g}$ RNA with SuperScript III First-Strand kit (Invitrogen), and quantified by real-time RT-PCR with Power SYBR Green PCR Master Mix (Applied Biosystems) using JFH-1 HCV RNA specific primers (Table 1 ) according to manufacturer's instructions. Assays were repeated with three independent replicates, and results are expressed as means \pm standard error of JFH-1 HCV RNA levels in media from infected cells transfected with analogs before or after infection compared to untreated controls.

\section{Results}

Table 2 shows the sequence of all RNA structural analogs. Analogs X-94 and X-12 were $100 \%$ and $59 \%$ identical to HCV genotype $1 \mathrm{~b}$, respectively, but were only $94 \%$ and $12 \%$ identical to the JFH-1 HCV genome, respectively. Analog
X-12c was $50 \%$ identical to HCV genotype $1 \mathrm{~b}$, and $0 \%$ identical to the JFH-1 HCV genome.

To determine whether short RNA sequences predicted to fold into secondary structural analogs of the $X$ region of HCV RNA genome could inhibit HCV replication, plasmids expressing RNA analogs X-94, X-12, and X-12c were transfected in replicon cells. Fig. 2 shows that the effects of transfection of plasmids expressing RNA structural analogs were dosedependent and most effective at $16 \mu \mathrm{g}$ of plasmid. Higher doses did not increase effects beyond those at $16 \mu \mathrm{g}$, and based on this information, $16 \mu \mathrm{g}$ of each plasmid was used for transfection for subsequent experiments. 3-(4,5-dimethyIthiazol-2-YI)-2,5-diphenyltetrazolium bromide (MTT) assays showed no significant toxic effects due to DNA transfection (data not shown).

Fig. 3 shows that transfection of plasmids generating RNA analogs affected HCV RNA levels in replicon cells. After transfection of $5 B-74,5 B-46, X-94, X-12$, and X-12C at $16 \mu \mathrm{g}, \mathrm{HCV}$ RNA levels were decreased to $42 \%, 55 \%, 52 \%$, $53 \%$, and $54 \%$, respectively, compared to levels of untreated controls. These differences were significant $(p<0.001$ for all). An unrelated control plasmid (HB) generating an HBV sequence had no significant effect under identical conditions. Furthermore, combinations of $5 B-74$ plus $X-94$ and $5 B-46$ plus $\mathrm{X}-12$ administered at the same total dose, and under identical conditions, decreased HCV RNA levels to $21 \%$ and $30 \%$, $(p<0.001)$, respectively, compared to untreated controls (Fig. 3). These levels of inhibition for the combinations were greater than that for any individual analog alone.

The X-region analog is $98 \mathrm{nt}$ long. We wondered whether smaller structural elements could be produced that retained inhibitory effects. To test this hypothesis, two smaller analogs, $\mathrm{X}-12 \mathrm{a}$ and $\mathrm{X}-12 \mathrm{~b}$, were created that corresponded to nt 1-55 and nt 56-95 regions, respectively, of analog X-12 (Fig. 1C). Transfection with $\mathrm{X}-12 \mathrm{a}$ decreased HCV RNA to $58 \%$, about the same as intact $X-12(p<0.001)$. However, the other fragment, $X-12 b$, was much less effective, resulting in a level of only $78 \%$ and not significantly different from untreated control. A combination of $X-12 a$ plus $X-12 b$ inhibited levels to $60 \%$ of untreated controls, which was similar to the effects of X-12a alone (Fig. 4). The data suggested that the $X-12$ a region was the portion of the $X$ analog that was responsible for the majority of the inhibitory 
Gupta N. et al: RNA structures involved in viral replication

Table 3. Percent identity of RNA structural analogs with HCV genotypes 1b and 2a (dG: free energy)

\begin{tabular}{|c|c|c|}
\hline Analog & HCV1b & $\mathrm{HCV} 2 \mathrm{a}$ \\
\hline $\begin{array}{l}X-94 \\
(\mathrm{dG}=-46.70 \mathrm{kcal} / \mathrm{mol})\end{array}$ & $100 \%$ & $94 \%$ \\
\hline $\begin{array}{l}\mathrm{X}-12 \\
(\mathrm{dG}=-47.40 \mathrm{kcal} / \mathrm{mol})\end{array}$ & $59 \%$ & $12 \%$ \\
\hline $\begin{array}{l}X-12 \mathrm{c} \\
(\mathrm{dG}=-47.50 \mathrm{kcal} / \mathrm{mol})\end{array}$ & $50 \%$ & No significant identity \\
\hline
\end{tabular}

activity. The $\mathrm{X}-12 \mathrm{~b}$ region appeared to contribute little to $\mathrm{X}$ analog activity.

To determine whether RNA structural analogs were also effective in an infection model and against a different HCV genotype, a JFH-1 infection model was studied. Fig. 5 shows that the levels in untreated controls increased progressively, and by $12 \mathrm{~h}$, exceeded the level of input HCV RNA levels by 6 fold (extreme left bars) at $72 \mathrm{~h}$. In contrast, Huh7.5 cells transfected with analogs 5B-74, 5B-46, X-94, and X-12 and infected with JFH-1 $48 \mathrm{~h}$ later, inhibited HCV RNA levels to $5.9 \%, 6.2 \%, 6.6 \%$, and $1.8 \%$, respectively, compared to untreated controls $(p<0.001)$. Even after $72 \mathrm{~h}$, no cells treated with analogs had HCV RNA levels that exceeded more than $30 \%$ of input levels.

To determine whether RNA structural analogs could inhibit a pre-existing $\mathrm{HCV}$ infection, cells were infected with $\mathrm{JFH}-1$ $\mathrm{HCV}$ for $8 \mathrm{~h}$ and then transfected with analogs HB, 5B-74, 5B$46, X-94$, and X-12. Medium was tested for JFH-1 HCV RNA post-transfection at various time points. Fig. 6 shows that there was a progressive increase in JFH-1 HCV RNA levels with time in the media compared to uninfected controls. HCV RNA levels exceeded those of input virus at $12 \mathrm{~h}$ posttransfection and were four-fold higher by $72 \mathrm{~h}$. However, $72 \mathrm{~h}$ after transfection with analogs 5B-74, 5B-46, X-94, and $\mathrm{X}-12$; HCV RNA levels were $8.8 \%, 10.5 \%, 9.0 \%$, and $11.6 \%$, respectively, compared to untreated controls.

\section{Discussion}

Many previous studies, including our own, have shown that specific domains of the genomes of some RNA viruses are critical for viral translation and replication. ${ }^{30-32}$ The NS5B

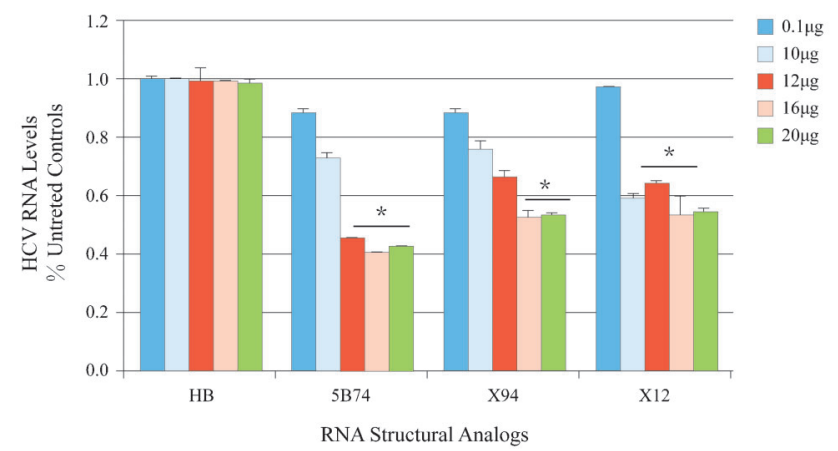

Fig. 2. HCV RNA levels in replicon cells $48 \mathrm{~h}$ post-transfection with structural analogs. Replicon cells were transfected with various concentrations of plasmids expressing HB, 5B-74, X-94, and X-12. HCV RNA levels were quantified in cell lysates by qRT-PCR $48 \mathrm{~h}$ post-transfection. The values represent HCV1b RNA levels in transfected cells compared to untreated controls $(n=4)$, $* p<0.001$. coding region of the HCV genome adopts a stem-loop structure that is involved in the replication of HCV. Expression of RNA structural analogs predicted to mimic the stem-loop structure identical to the NS5B region of the HCV genome was able to inhibit replication of HCV genotype $2 a{ }^{12}$ The current study confirms previous reports that RNA secondary structure is important for HCV RNA replication. ${ }^{16,33}$ Conserved genomic RNA sequences have been shown to fold to adopt stem-loop motifs that interact with other RNA motifs and/or proteins required for translation and replication. 10,31,34-37 Identification of such RNA sequences and determination of secondary structure formed by these sequences are challenging because structural motifs depend on various parameters, including host cellular microenvironments and the presence of other host and viral interacting molecules. ${ }^{29,38-40}$ Several types of software have been developed to predict the stable structures formed by RNA sequences based on thermodynamic parameters. The current data generated by Mfold software confirm our previous findings that structures predicted using these twodimensional models do have substantial inhibitory activity against $\mathrm{HCV}$ replication. It is also clear that the actual molecules exist not in a two-dimensional but a three-dimensional state, and it is the latter that causes the inhibitory activity. Such structures cannot be predicted by the current software. Nevertheless, the data support the notion that two-dimensional structures are related to and can predict the activity of analogs in three-dimensions.

We intentionally studied models of two different HCV genotypes. The structural analogs were effective in models of both genotype 1 and 2 viruses, suggesting that because the design of the molecules was based on secondary rather than primary structure, the effects are more likely to be multigenotypic. This may be clinically relevant as it has already

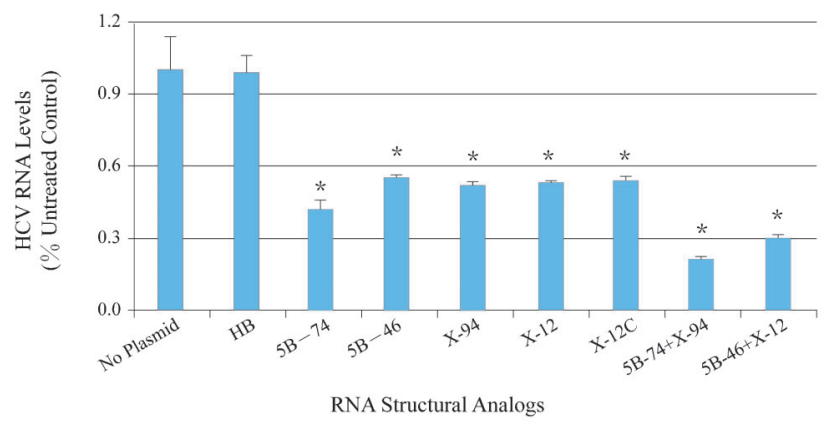

Fig. 3. HCV RNA levels in replicon cells $48 \mathrm{~h}$ post-transfection with structural analogs. Replicon cells were transfected with $H B, 5 B-74, X-94, X-12$, $\mathrm{X}-12 \mathrm{c}, 5 \mathrm{~B}-74$ plus $\mathrm{X}-94$, and $5 \mathrm{~B}-46$ plus $\mathrm{X}-12$, and HCV RNA levels were quantified in cell lysates by qRT-PCR $48 \mathrm{~h}$ post-transfection. The figure represents HCV $1 \mathrm{~b}$ RNA levels in transfected cells compared to untreated controls $(n=4), * p<0.001$. 


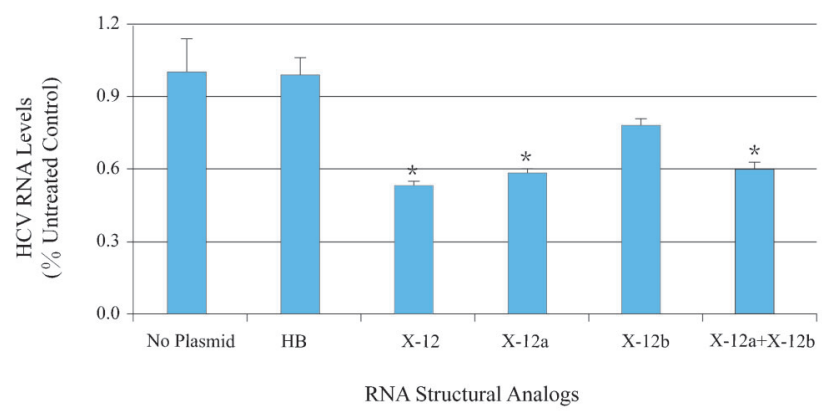

Fig. 4. HCV RNA levels in replicon cells $48 \mathrm{~h}$ post-transfection with structural analogs. Replicon cells were transfected with HB, 5B-74, X-12a, X$12 b$, and $X-12 a$ plus $X-12 b$, and HCV RNA levels were quantified in cell lysates by qRT-PCR $48 \mathrm{~h}$ post-transfection. The figure represents HCV 1b RNA levels in transfected cells compared to untreated controls $(n=4), * p<0.001$.

been demonstrated that some current direct acting antiviral agents vary in efficacy against HCV genotypes ${ }^{41,42}$ and even subtypes. ${ }^{43}$ Design of novel anti-HCV agents based on secondary structural considerations may offer a strategy to develop new agents that are independent of viral genotype or subtype.

For HCV genotype 1 b studies, a replicon cell model with an integrated $\mathrm{HCV}$ genome was used to constitutively generate subgenomic HCV1b replicons in Huh7.5 cells. ${ }^{20}$ This system has been used extensively to determine the effects of various drugs and proteins on viral replication and infection. ${ }^{44,45}$ However, because HCV RNA replication in this model is constitutive, it is not a simulation of HCV infection. For this reason, we examined here the effects of structural analogs on $\mathrm{JFH} 1$, to provide a more realistic $\mathrm{HCV}$ infection model system. ${ }^{24,46,47}$ The results from the JFH-1 infection model systems offered insight into the differences in efficacy among structural analogs depending on whether they were introduced before or after viral infection. The JFH-1 HCV infection system has been used to determine the anti-HCV activity of several proteins and inhibitors (example: Raloxifene, NSC compounds) before or after infection of hepatic cells. ${ }^{48,49}$ Introduction of RNA structural analogs after viral infection resembles treatment strategies for hepatocytes already infected with HCV, while exposure of cells before viral infection represents a potential prophylactic approach.

Expression of the stem-loop structure of X-region in the $3^{\prime}$-UTR of HCV genome (using RNA analogs X-94, X-12, and $\mathrm{X}-12 \mathrm{c}$ ) was found to be effective against HCV replication, regardless of the sequence of RNA. Furthermore, we have identified a small portion, one of the stem-loop structures of the $\mathrm{X}$-region, $\mathrm{X}-12 \mathrm{a}$, as the smallest identified portion of the $\mathrm{X}$ region analog that retains inhibitory activity. The other stemloop structure, $\mathrm{X}-12 \mathrm{~b}$ of approximately the same length; which also possesses natural HCV sequences, was virtually ineffective. These data confirmed that a specific structure, the stemloop conformation, was involved, and that the observed inhibitory effects were not due a nonspecific interaction of $\mathrm{HCV}$ sequences. The studies on nucleotide base substitution in the $\mathrm{X}$-region showing reduction in the identity to the natural $\mathrm{HCV}$ sequence to less than $50 \%$, while retaining secondary structure, indicated that the observed inhibitory effects did not likely involve anti-sense mechanisms. These results are consistent with previous studies. ${ }^{12,50}$

\section{Conclusions}

The data indicate that conformation of secondary structures in 3'-UTR of HCV RNA genome is required for HCV replication. Stable expression of RNA analogs predicted to have identical

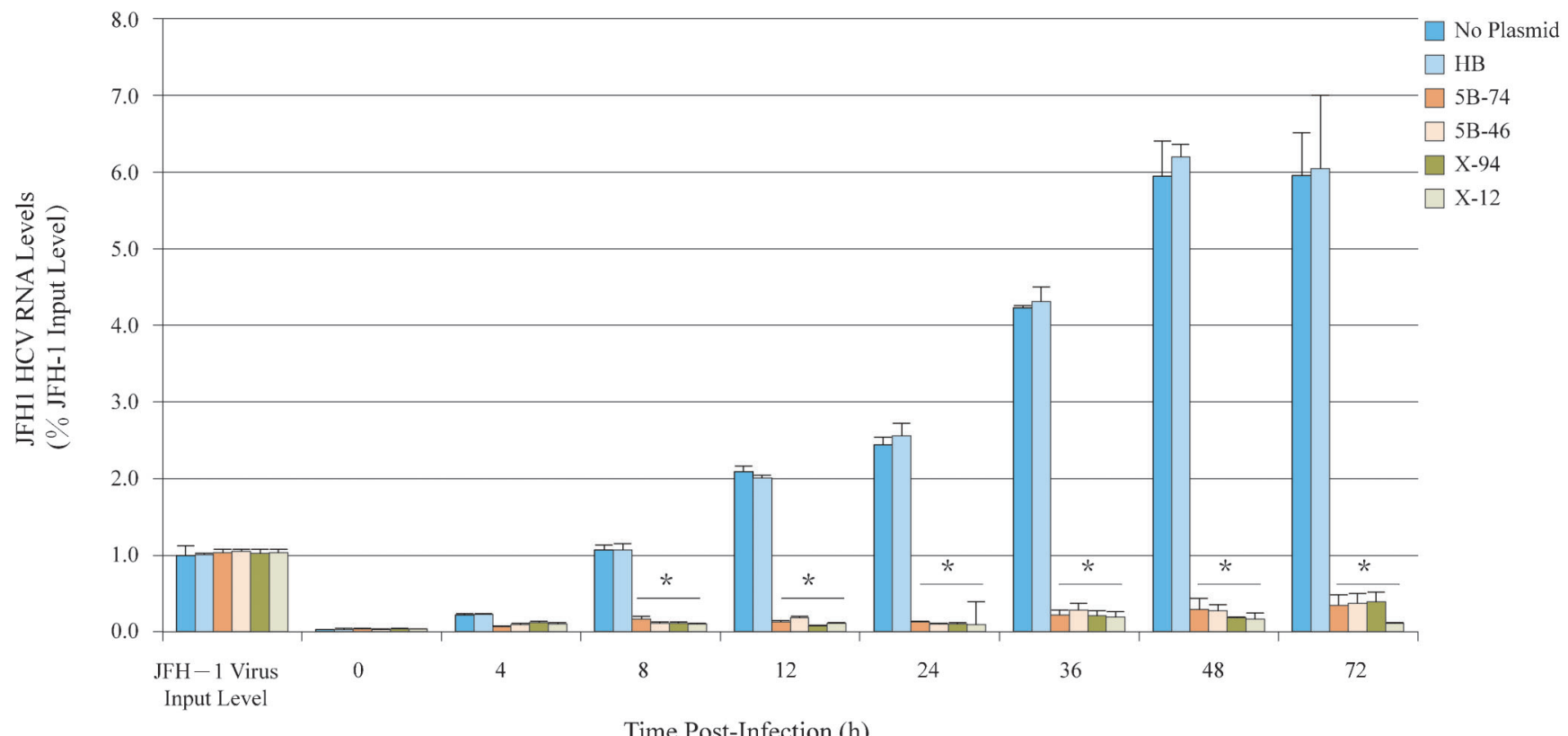

Fig. 5. JFH-1 HCV RNA levels in media from Huh7.5 cells at various time points post-infection. Huh7.5 cells were transfected with analogs HB, 5B-74, 5B-46, X-94, and $\mathrm{X}-12$ and then infected with JFH-1 HCV $48 \mathrm{~h}$ post-transfection. HCV RNA levels in media were quantified by qRT-PCR at various time points post-infection. The values represent JFH-1 HCV RNA levels in media from cells transfected with analogs $48 \mathrm{~h}$ before infection compared to untreated controls at various time points $(n=3), * p<0.001$. 
Gupta N. et al: RNA structures involved in viral replication

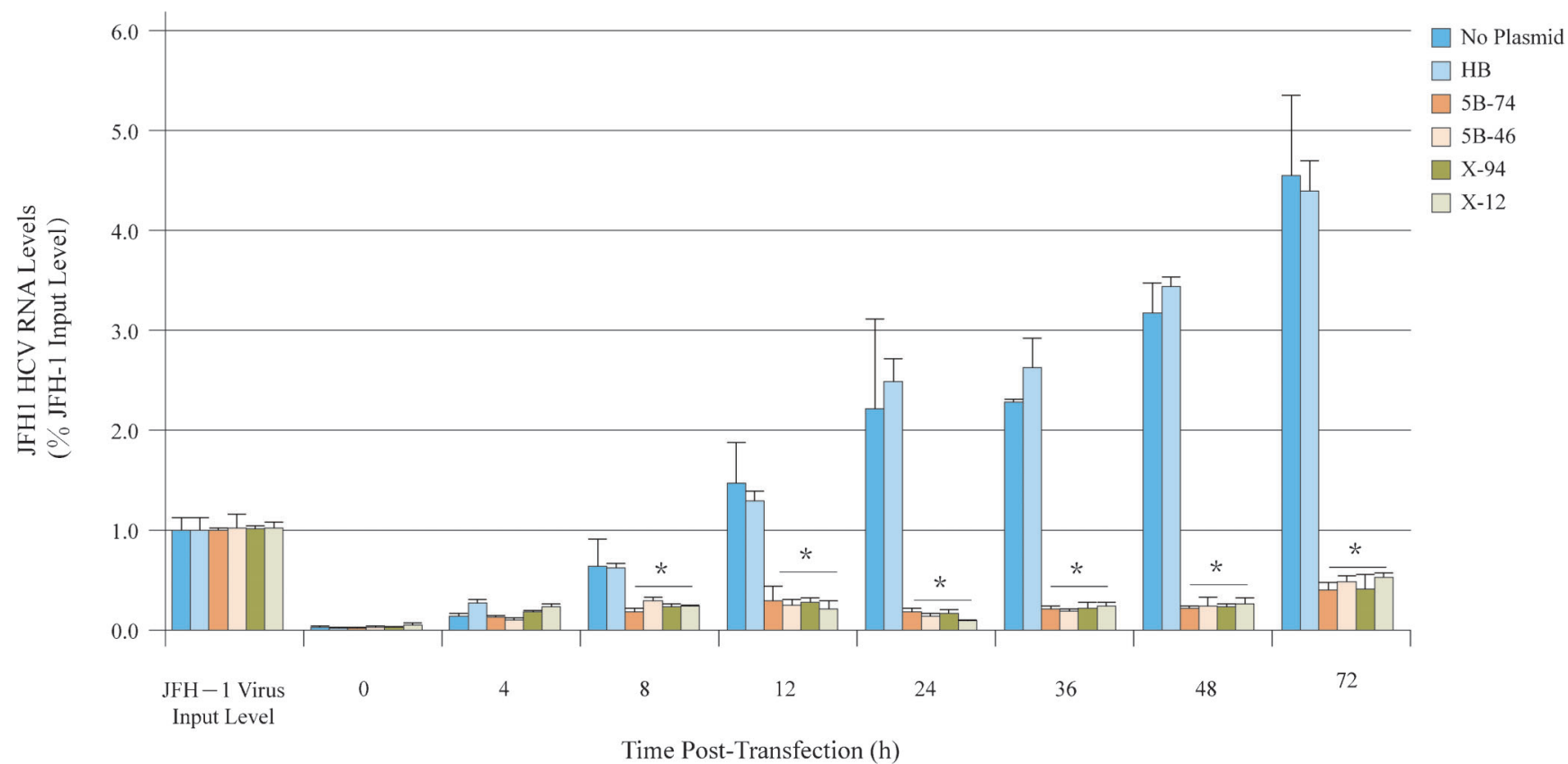

Fig. 6. JFH-1 HCV RNA levels in media from Huh7.5 cells at various time points post-transfection. Huh7.5 cells infected with JFH-1 HCV, and then transfected with analogs HB, 5B-74, 5B-46, X-94 and X-12 $8 \mathrm{~h}$ post-infection. HCV RNA levels in media from infected cells were quantified by qRT-PCR at various time points posttransfection. The figure represents JFH-1 HCV RNA levels in media from infected cells transfected with analogs $8 \mathrm{~h}$ post-infection compared to untreated controls at various time points $(n=3), * p<0.001$

stem-loop structures, but sequences vastly different from HCV genomic RNA, might inhibit HCV infection of hepatocytes in liver, and may represent a novel approach to design antiHCV agents.

\section{Acknowledgments}

We thank Dr. Charles Rice (Rockefeller University, NY, USA) for providing Huh7.5 cells, Dr. Takaji Wakita (National Institute of Infectious Diseases, Tokyo, Japan) for generous donation of HCV JFH-1 CDNA, and Amy Pallotti and Annilise Larosa for their secretarial assistance.

\section{Conflict of interest}

George Y. Wu serves on medical advisory boards for Gilead, Janssen, and Bristol-Myers Squibb.

\section{Author contributions}

Conceiving the study and contributing interpretation of data (GYW), designing and performing the research, as well as writing the manuscript (NG), contributing technical advice and review of manuscript $(\mathrm{CHW})$.

\section{References}

[1] Alter MJ. Epidemiology of hepatitis C virus infection. World J Gastroenterol 2007:13:2436-2441. doi: 10.3748/wjg.v13.i17.2436.

[2] Lauer GM, Walker BD. Hepatitis C virus infection. N Engl J Med 2001;345:4152. doi: 10.1056/NEJM200107053450107.
[3] Chakravarti A, Dogra G, Verma V, Srivastava AP. Distribution pattern of HCV genotypes \& its association with viral load. Indian J Med Res 2011;133:326331.

[4] Hnatyszyn $\mathrm{HJ}$. Chronic hepatitis $\mathrm{C}$ and genotyping: the clinical significance of determining HCV genotypes. Antivir Ther 2005;10:1-11.

[5] Pang PS, Planet PJ, Glenn JS. The evolution of the major hepatitis C genotypes correlates with clinical response to interferon therapy. PLoS One 2009; 4:e6579. doi: 10.1371/journal.pone.0006579.

[6] You S, Stump DD, Branch AD, Rice CM. A cis-acting replication element in the sequence encoding the NS5B RNA-dependent RNA polymerase is required for hepatitis C virus RNA replication. J Virol 2004;78:1352-1366. doi: 10.1128 /JVI.78.3.1352-1366.2004

[7] Piñeiro D, Martinez-Salas E. RNA structural elements of hepatitis C virus controlling viral RNA translation and the implications for viral pathogenesis. Viruses 2012;4:2233-2250. doi: 10.3390/v4102233.

[8] Ray PS, Das S. Inhibition of hepatitis C virus IRES-mediated translation by small RNAs analogous to stem-loop structures of the $5^{\prime}$-untranslated region. Nucleic Acids Res 2004;32:1678-1687. doi: 10.1093/nar/gkh328.

[9] Kolykhalov AA, Mihalik K, Feinstone SM, Rice CM. Hepatitis C virus-encoded enzymatic activities and conserved RNA elements in the $3^{\prime}$ nontranslated region are essential for virus replication in vivo. J Virol 2000;74:2046-2051. doi: 10.1128/JVI.74.4.2046-2051.2000.

[10] Luo G, Xin S, Cai Z. Role of the $5^{\prime}$-proximal stem-loop structure of the 5 untranslated region in replication and translation of hepatitis C virus RNA J Virol 2003;77:3312-3318. doi: 10.1128/JVI.77.5.3312-3318.2003.

[11] Dutkiewicz M, Swiatkowska A, Figlerowicz M, Ciesiołka J. Structural domains of the $3^{\prime}$-terminal sequence of the hepatitis $C$ virus replicative strand. Biochemistry 2008;47:12197-12207. doi: 10.1021/bi800348g.

[12] Smolic R, Smolic M, Andorfer JH, Wu CH, Smith RM, Wu GY. Inhibition of hepatitis $\mathrm{C}$ virus replication by single-stranded RNA structural mimics. World J Gastroenterol 2010;16:2100-2108. doi: 10.3748/wjg.v16.i17.2100.

[13] Smith RM, Wu GY. Structure-based design of hepatitis $C$ virus inhibitors. J Viral Hepat 2003;10:405-412. doi: 10.1046/j.1365-2893.2003.00443.x.

[14] Smith RM, Walton CM, Wu CH, Wu GY. Secondary structure and hybridization accessibility of hepatitis C virus 3 '-terminal sequences. J Virol 2002;76: 9563-9574. doi: 10.1128/JVI.76.19.9563-9574.2002.

[15] Zhang J, Yamada O, Sakamoto T, Yoshida H, Araki H, Murata T, et al. Inhibition of hepatitis $\mathrm{C}$ virus replication by pol III-directed overexpression of RNA decoys corresponding to stem-loop structures in the NS5B coding region. Virology 2005;342:276-285. doi: 10.1016/j.virol.2005.08.003. 
[16] Kolykhalov AA, Feinstone SM, Rice CM. Identification of a highly conserved sequence element at the 3 ' terminus of hepatitis $C$ virus genome RNA. J Virol $1996 ; 70: 3363-3371$.

[17] Blight KJ, Rice CM. Secondary structure determination of the conserved 98base sequence at the $3^{\prime}$ terminus of hepatitis $C$ virus genome RNA. J Virol $1997 ; 71: 7345-7352$

[18] Ito T, Lai MM. Determination of the secondary structure of and cellular protein binding to the $3^{\prime}$-untranslated region of the hepatitis C virus RNA genome. J Virol 1997;71:8698-8706.

[19] Huang L, Hwang J, Sharma SD, Hargittai MR, Chen Y, Arnold JJ, et al. Hepatitis $C$ virus nonstructural protein 5A (NS5A) is an RNA-binding protein. J Biol Chem 2005;280:36417-36428. doi: 10.1074/jbc.M508175200.

[20] Lohmann V, Hoffmann S, Herian U, Penin F, Bartenschlager R. Viral and cellular determinants of hepatitis C virus RNA replication in cell culture. J Virol 2003;77:3007-3019. doi: 10.1128/JVI.77.5.3007-3019.2003.

[21] Lohmann V, Körner F, Koch J, Herian U, Theilmann L, Bartenschlager R. Replication of subgenomic hepatitis $C$ virus RNAs in a hepatoma cell line. Science 1999;285:110-113. doi: 10.1126/science.285.5424.110.

[22] Kato T, Date T, Miyamoto M, Furusaka A, Tokushige K, Mizokami M, et al. Efficient replication of the genotype 2 a hepatitis $C$ virus subgenomic replicon. Gastroenterology 2003;125:1808-1817. doi: $10.1053 /$ j.gastro. 2003 .09.023.

[23] Wakita T, Pietschmann T, Kato T, Date T, Miyamoto M, Zhao Z, et al. Production of infectious hepatitis $\mathrm{C}$ virus in tissue culture from a cloned viral genome. Nat Med 2005;11:791-796. doi: 10.1038/nm1268.

[24] Kato T, Date T, Murayama A, Morikawa K, Akazawa D, Wakita T. Cell culture and infection system for hepatitis C virus. Nat Protoc 2006;1:2334-2339. doi: $10.1038 /$ nprot.2006.395

[25] Blight KJ, McKeating JA, Rice CM. Highly permissive cell lines for subgenomic and genomic hepatitis C virus RNA replication. J Virol 2002;76:1300113014. doi: 10.1128/JVI.76.24.13001-13014.2002.

[26] Suzuki T, Aizaki H, Murakami K, Shoji I, Wakita T. Molecular biology of hepatitis C virus. J Gastroenterol 2007;42:411-423. doi: 10.1007/s00535007-2030-3

[27] Zuker M. Mfold web server for nucleic acid folding and hybridization prediction. Nucleic Acids Res 2003;31:3406-3415. doi: 10.1093/nar /gkg595.

[28] Doshi KJ, Cannone J], Cobaugh CW, Gutell RR. Evaluation of the suitability of free-energy minimization using nearest-neighbor energy parameters for RNA secondary structure prediction. BMC Bioinformatics 2004;5:105. doi: 10.1186/1471-2105-5-105

[29] Mathews DH, Sabina J, Zuker M, Turner DH. Expanded sequence dependence of thermodynamic parameters improves prediction of RNA secondary structure. J Mol Biol 1999;288:911-940. doi: 10.1006/jmbi.1999.2700.

[30] Hofacker IL, Stadler PF, Stocsits RR. Conserved RNA secondary structures in viral genomes: a survey. Bioinformatics 2004;20:1495-1499. doi: 10.1093 /bioinformatics/bth108.

[31] Kieft JS. Viral IRES RNA structures and ribosome interactions. Trends Biochem Sci 2008;33:274-283. doi: 10.1016/j.tibs.2008.04.007.

[32] Gamarnik AV, Andino R. Switch from translation to RNA replication in a positive-stranded RNA virus. Genes Dev. 1998;12:2293-2304. doi: 10.1101/gad.12.15.2293.

[33] Han JH, Shyamala V, Richman KH, Brauer MJ, Irvine B, Urdea MS, et al. Characterization of the Terminal Regions of Hepatitis C Viral RNA: Identification of Conserved Sequences in the $5^{\prime}$ Untranslated Region and Poly(a) Tails at the 3' End. Proc Natl Acad Sci USA 1991;88:1711-1715. doi: 10.1073/pnas.88.5.1711.

[34] Blackham SL, McGarvey MJ. A host cell RNA-binding protein, Staufen1, has a role in hepatitis C virus replication before virus assembly. J Gen Virol 2013; 94:2429-2436. doi: 10.1099/vir.0.051383-0.
[35] Wang L, Jeng KS, Lai MM. Poly(C)-Binding Protein 2 Interacts with Sequences Required for Viral Replication in the Hepatitis C Virus (HCV) 5' Untranslated Region and Directs HCV RNA Replication through Circularizing the Viral Genome. J Virol 2011;85:7954-7964. doi: 10.1128/JVI.00339-11.

[36] Ito T, Lai MM. An internal polypyrimidine-tract-binding protein-binding site in the hepatitis C virus RNA attenuates translation, which is relieved by the $3^{\prime}$ untranslated sequence. Virology 1999;254:288-296. doi: 10.1006/viro .1998.9541.

[37] Anjum S, Ali S, Ahmad T, Afzal MS, Waheed Y, Shafi T, et al. Sequence and structural analysis of $3^{\prime}$ untranslated region of hepatitis $C$ virus, genotype $3 a$, from pakistani isolates. Hepat Mon 2013;13:e8390. doi: 10.5812/hepatmon .8390 .

[38] Fontana W, Konings DA, Stadler PF, Schuster P. Statistics of Rna Secondary Structures. Biopolymers 1993;33:1389-1404. doi: 10.1002/bip .360330909 .

[39] Fontana W, Griesmacher T, Schnabl W, Stadler PF, Schuster P. Statistics of Landscapes Based on Free-Energies, Replication and Degradation Rate Constants of Rna Secondary Structures. Monatsh Chem 1991;122:795819. doi: 10.1007/BF00815919.

[40] Butcher SE, Pyle AM. The Molecular Interactions That Stabilize RNA Tertiary Structure: RNA Motifs, Patterns, and Networks. Acc Chem Res 2011;44: 1302-1311. doi: 10.1021/ar200098t.

[41] Kamal SM. Pharmacogenetics of hepatitis C: transition from interferon-based therapies to direct-acting antiviral agents. Hepat Med 2014;6:61-77. doi: 10.2147/HMER.S41127.

[42] Bartels DJ, Sullivan JC, Zhang EZ, Tigges AM, Dorrian JL, De Meyer S, et al. Hepatitis $C$ virus variants with decreased sensitivity to direct-acting antivirals (DAAs) were rarely observed in DAA-naive patients prior to treatment. J Virol 2013;87:1544-1553. doi: 10.1128/JVI.02294-12.

[43] Wyles DL, Gutierrez JA. Importance of HCV genotype 1 subtypes for drug resistance and response to therapy. J Viral Hepat 2014;21:229-240. doi: $10.1111 /$ jvh.12230.

[44] Ludmerer SW, Graham DJ, Boots E, Murray EM, Simcoe A, Markel EJ, et al. Replication fitness and NS5B drug sensitivity of diverse hepatitis $C$ virus isolates characterized by using a transient replication assay. Antimicrob Agents Chemother 2005;49:2059-2069. doi: 10.1128/AAC.49.5.20592069.2005.

[45] Gu B, Gates AT, Isken O, Behrens SE, Sarisky RT. Replication studies using genotype 1 a subgenomic hepatitis $C$ virus replicons. J Virol 2003;77:53525359. doi: 10.1128/JVI.77.9.5352-5359.2003.

[46] Zhong J, Gastaminza P, Cheng G, Kapadia S, Kato T, Burton DR, et al. Robust hepatitis C virus infection in vitro. Proc Natl Acad Sci USA 2005;102:92949299. doi: 10.1073/pnas.0503596102.

[47] Date T, Miyamoto M, Kato T, Morikawa K, Murayama A, Akazawa D, et al. An infectious and selectable full-length replicon system with hepatitis $C$ virus JFH-1 strain. Hepatol Res 2007;37:433-443. doi: 10.1111/j.1872-034X .2007.00056.x.

[48] Takeda M, Ikeda M, Mori K, Yano M, Ariumi Y, Dansako $H$, et al. Raloxifene inhibits hepatitis $C$ virus infection and replication. FEBS Open Bio 2012;2: 279-283. doi: 10.1016/j.fob.2012.08.003.

[49] Yu X, Sainz B Jr, Petukhov PA, Uprichard SL. Identification of hepatitis C virus inhibitors targeting different aspects of infection using a cell-based assay. Antimicrob Agents Chemother 2012;56:6109-6120. doi: 10.1128/AAC .01413-12.

[50] Tuplin A, Evans DJ, Simmonds P. Detailed mapping of RNA secondary structures in core and NS5B-encoding region sequences of hepatitis C virus by RNase cleavage and novel bioinformatic prediction methods. J Gen Virol 2004;85:3037-3047. doi: 10.1099/vir.0.80141-0. 